\title{
Review
}

\section{Zero tolerance for complacency by government of West African countries in the face of COVID-19}

\author{
O. Erhabor ${ }^{\mathrm{a}, *}$, T. Erhabor ${ }^{\mathrm{b}}$, T.C. Adias $^{\mathrm{c}}$, G.C. Okara ${ }^{\mathrm{d}}$ and M. Retsky $^{\mathrm{e}}$ \\ ${ }^{a}$ Department of Haematology, SMLS, Usmanu Danfodiyo University, Sokoto, Nigeria \\ ${ }^{\mathrm{b}}$ Medical Laboratory Science Council of Nigeria, Nigeria \\ ${ }^{\mathrm{c}}$ Federal University Otuoke Bayelsa State, Nigeria \\ ${ }^{\mathrm{d}}$ West African Postgraduate College of Medical Laboratory Science, Nigeria \\ ${ }^{\mathrm{e}}$ Harvard School of Public Health, Boston, MA, USA
}

\begin{abstract}
A novel Coronavirus (SARS-CoV-2) causing a cluster of respiratory infections (Coronavirus Disease 2019, COVID-19) first discovered in Wuhan, China, is responsible for a new illness that has been found to affect the lungs and airways of patients with associated symptoms of fever, cough and shortness of breath. In the light of few cases recorded so far in West Africa there is tendency for complacency. The region needs to make strategic plans based on available evidence to enable them effectively deal with this rapidly evolving pandemic. At this very moment countries like China, Italy, France, Spain, Iran, UK and many others are witnessing sustained and intensive community transmission of this virus and increasing numbers of severe disease and death particularly among elderly patients with other comorbidities. The reality of the seriousness of this pandemic is alarming. Government of member states of ECOWAS need to prepare themselves by building capacity as well as implement evidenced-based steps to mitigate this rapidly evolving pandemic by testing persons presenting with symptoms (fever, cough and shortness of breath), isolating and treating those found positive, tracing and quarantining contacts, implementing social distancing as well as optimizing human and material endowment to allow healthcare workers offer safe quality clinical care for affected patients to prevent secondary infection among healthcare workers.
\end{abstract}

Keywords: Zero tolerance, complacency, government, West Africa, COVID-19 pandemic

\section{Introduction}

The Merriam-Webster dictionary defined complacency as self-satisfaction especially when accompanied by unawareness of actual dangers or deficiencies [1]. When it comes to safety, complacency can be dangerous. Pandemics are large-scale outbreaks of infectious disease that can greatly increase morbidity and mortality over a wide geographic area and cause significant

\footnotetext{
${ }^{*}$ Corresponding author: O. Erhabor, West African Postgraduate College of Medical Laboratory Science, Department of Haematology, SMLS, Usmanu Danfodiyo University, Sokoto, Nigeria. Tel.: +234 813962 5990; E-mail: n_osaro@yahoo.com.
}

economic, social, and political disruption [2]. A novel coronavirus (SARS-CoV-2) causing a cluster of respiratory infections (Coronavirus disease 2019, COVID19 ) in Wuhan, China (a city of more than 11 million people and the capital of Hubei province in China), was identified on 7 January 2020 [3]. Twenty-seven patients with pneumonia had initially been reported, with an epidemiological link to a live animal market that was closed and disinfected on 1 January. From 20 January, the number of notifications of cases rose dramatically, and as at $12^{\text {th }}$ of February $2020,45,179$ cases of SARS-CoV-2 have been confirmed, including 1,116 deaths. Most of the cases $(n=44,665)$ were reported in 31 provinces and autonomous regions of China and 514 cases were reported in 25 other countries 
in Asia, Australia, Europe and North America [4]. To date, the primary source of infection remains unknown and could still be active. Human-to-human transmission was observed early after the emergence of this new virus in China and abroad, including family clusters and healthcare settings. The current outbreak dynamics strongly indicate sustained human-to-human transmission. SARS Coronavirus-2 [5] has been identified by the International Committee of Taxonomy of Viruses (ICTV) as the cause of the disease COVID19 [6]. SARS-CoV-2 is responsible for this new illness that has been found to affect the lungs and airways of patients with associated symptoms of fever, cough and shortness of breath. The Advisory Committee on Dangerous Pathogens (ACDP) in the UK has provisionally classed COVID-19 or SARS-CoV-2 as a hazard group 3 (HG3) organisms. Biological agents are often classified into four Hazard Groups (HG1-4) based on how infective the organism is, likelihood of spread within the community and availability/requirement of effective prophylaxis or treatment. COVID-19 was first reported as pneumonia of unknown origin in Wuhan, China. The outbreak was officially reported to the WHO Country Office in China on 31 December 2019. The outbreak was later declared a Public Health Emergency of International Concern (PHEIC) by the WHO [7,8]. On 30 January 2020, WHO found evidence of local transmission of the disease in many countries across all six WHO regions $[9,10]$. Coronaviruses have been reported to cause mild respiratory disease in humans (HCoV-229E, HCoV-NL63, HCoV-HKU1 and HCoVOC43 [11]. The zoonotic Middle East respiratory syndrome coronavirus (MERS-CoV) and severe acute respiratory syndrome coronavirus (SARS-CoV) has been shown to cause disease in animals. There is limited information on the SARS-CoV-2 (pathogenicity, viral dynamics, immune response variables, the effect of sociodemographic factors on disease severity, relationship between viral concentration and disease severity, development and validation of useful biomarkers and serological assays, biological response optimal timing and type of clinical material to sample for molecular testing, and transmission risks associated) and the associated COVID-19 disease it causes [12].

Since 31 December 2019 and as of 18 March 2020, 194909 cases of COVID-19 in accordance with the applied case definitions and testing strategies in the affected countries) have been reported across 5 continents (Africa, Asia, America, Europe and Oceania) and International conveyance in Japan resulting in more than 7876 deaths. The deaths have been reported from
China (3 242), Italy (2 505), Iran (988), Spain (491), France (175), United States (108), South Korea (86), United Kingdom (60), Japan (28), Netherlands (24), Switzerland (19), Philippines (14), Germany (13), Iraq (11), San Marino (11), Canada (8), Sweden (8), International conveyance in Japan (7), Algeria (5), Australia (5), Belgium (5), Greece (5), Indonesia (5), Poland (5), Denmark (4), Egypt (4), Taiwan (4), Austria (3), India (3), Lebanon (3), Norway (3), Argentina (2), Bulgaria (2), Ecuador (2), Ireland (2), Malaysia (2), Morocco (2), Albania (1), Bahrain (1), Brazil (1), Guatemala (1), Guyana (1), Hungary (1), Luxembourg (1), Panama (1), Portugal (1), Slovenia (1), Sudan (1) and Thailand (1) $[11]$.

\subsection{Cases have been reported on the following continents}

\subsubsection{Africa}

Egypt (166), South Africa (85), Algeria (60), Morocco (44), Senegal (31), Tunisia (24), Burkina Faso (20), Cameroon (10), Rwanda (7), Ghana (6), Côte d'Ivoire (5), Ethiopia (5), Kenya (4), Seychelles (4), Democratic Republic of the Congo (3), Nigeria (3), Liberia (2), Namibia (2), Benin (1), Central African Republic (1), Congo (1), Equatorial Guinea (1), Eswatini (1), Gabon (1), Gambia (1), Guinea (1), Mauritania (1), Somalia (1), Sudan (1), Togo (1) and United Republic of Tanzania (1).

\subsubsection{Asia}

China (81 163), Iran (16 169), South Korea (8 413), Japan (829), Malaysia (673), Qatar (442), Israel (427), Singapore (266), Bahrain (237), Pakistan (187), Philippines (187), Thailand (177), Indonesia (172), Iraq (154), India (137), Saudi Arabia (133), Kuwait (130), Lebanon (120), United Arab Emirates (113), Taiwan (77), Vietnam (61), Brunei Darussalam (56), Sri Lanka (42),

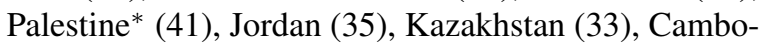
dia (24), Oman (24), Afghanistan (22), Uzbekistan (16), Maldives (13), Bangladesh (8), Mongolia (4), Bhutan (1), Nepal (1) and Myanmar (0).

\subsubsection{America}

United States (6 427), Canada (569), Brazil (291), Chile (201), Peru (117), Ecuador (111), Mexico (93), Panama (86), Argentina (79), Colombia (65), Costa Rica (50), Uruguay (50), Venezuela (33), Jamaica (13), Bolivia (12), Dominican Republic (11), Paraguay (11), Honduras (9), Cuba (7), Trinidad and Tobago (7), Guatemala (6), Guyana (4), Saint Lucia (2), Antigua and Barbuda (1), Bahamas (1), Barbados (1), Saint Vincent and the Grenadines (1) and Suriname (1) [11]. 


\subsubsection{Europe}

Italy (31 506), Spain (11 178), France (7 730), Germany (7 156), Switzerland (2 650), United Kingdom (1 950), Netherlands (1 705), Austria (1 332), Norway (1 308), Belgium (1 243), Sweden (1 167), Denmark (1 024), Portugal (448), Czech Republic (434), Greece (387), Finland (319), Ireland (292), Slovenia (275), Iceland (247), Poland (238), Estonia (225), Romania (217), Luxembourg (140), Russia (114), San Marino (104), Turkey (98), Slovakia (97), Bulgaria (81), Armenia (78), Serbia (72), Croatia (69), Latvia (61), Albania (55), Hungary (50), Cyprus (40), Malta (38), Belarus (36), Georgia (34), North Macedonia (31), Moldova (30), Azerbaijan (28), Lithuania (25), Bosnia and Herzegovina (21), Kosovo** (19), Andorra (14), Ukraine (14), Monaco (9), Liechtenstein (7), Montenegro (2) and Holy See (1) [11].

\subsubsection{Oceania}

Australia (454) and New Zealand (20).

\subsubsection{Other}

International conveyance in Japan (696).

\subsection{Can West African countries manage COVID-19 outbreak with her weak health infrastructure?}

The United Nations defines Western Africa as the 16 countries of Benin, Burkina Faso, Cape Verde, The Gambia, Ghana, Guinea, Guinea-Bissau, Ivory Coast, Liberia, Mali, Mauritania, Niger, Nigeria, Senegal, Sierra Leone and Togo, as well as the United Kingdom Overseas Territory of Saint Helena, Ascension and Tristan da Cunha. The population of West Africa is estimated at about 381 million [14,15] people as of 2018, and at $381,981,000$ as of 2017 , of which $189,672,000$ are female and 192,309,000 males [16]. The region is quite diverse (cultures, languages and religion). It is divided by colonial legacy of fragmentation by official language into Anglophone (English speaking), Francophone (French speaking) and Lusophone (Portuguesespeaking). Ebola crisis in West Africa in 2014 revealed a fragile, weak and broken healthcare delivery system bedevilled by many challenges (heavy burden of communicable and non-communicable diseases; lack of due diligence and rampant corruption in medical products and technologies procurement [17]; low health coverage particularly in rural community; under-resourced health systems; poor leadership and governance [18]; suboptimal number of health healthcare workforce and poor remuneration and associated brain drain [19]; lack of inclusiveness and poor harmonious working relations among healthcare workers; poor embrace of modern technologies including information and communications technology (ICT) [20]; weak mechanisms for coordinating partner and counterpart funding related support [21]; lack of sustainable access to improved sanitation facilities and sustainable access to an improved water source [22]; poor information dissemination; poor contact tracing; poor implementation of national health insurance scheme; inefficiency in resource allocation and judicious use of health funds [23]; poor funding and lack of investment into healthcare delivery; inadequate health-related legislations and their enforcement; weak national health information and research systems [24]; limited community participation in planning, management and monitoring of health services; weak intersectorial action and horizontal and vertical inequities in health systems [25-28].

The ability of ECOWAS countries to achieve the health-related Millennium Development Goals has been greatly hampered by weak and poorly functioning health systems, among other challenges [29]. So far 2 countries in East and the West of Africa have recorded index cases of coronavirus pandemic. Somalia and Tanzania to the East and Liberia and Benin in West Africa. Benin reported its first coronavirus case via a government statement that disclosed that the said patient was a 49-year-old Burkinabe citizen who entered the country last week, March 12. Liberia on the other hand confirmed first the case of the virus imported by a government official who recently returned from Switzerland. Over in Tanzania, Health Minister confirmed the first case of a Tanzanian woman who only returned to the country yesterday [30]. The low cases reported so far in West Africa particularly with the suboptimal infrastructure in the region seem a heartening news. However, this should not call for complacency but should rather be seen as an opportunity to invest in preparedness to manage the pandemic to ensure that the spread is put under check. There is need for locally-driven, locally-generated evidence to guide, pandemic preparedness, health policy and systems decision-making and implementation [31]. Countries in West Africa tend to have suboptimal health infrastructure often due to decade of underinvestment. The response of most West African countries following the 2014 Ebola crisis brought to light how weak health infrastructure is in the region [32]. An already weak health workforce suffered a lot from this outbreak. Ebola outbreak started in December 2013 in Guinea and spread to Liberia and Sierra Leone in 2014. The health systems in place in 
the three countries lacked the infrastructure and the preparation to respond to the outbreak quickly and the World Health Organization (WHO) had no option than to declare it a public health emergency of international concern on August 2014 [33,34]. Health financing is indispensable to maintain and improve human welfare by ensuring workforce employment, availability of medicines and offering promotion and prevention public health programs [35]. Lack of adequate funds invested in health system infrastructure and purchase of supplies contributed to the poor management of the Ebola outbreak $[36,37]$. Lack of leadership at the national governmental level was the main reason that led to the poor coordination and absence of a prompt response [38]. Poor working conditions and salaries made healthcare workers flee to other countries when the Ebola outbreak started. This pattern was seen in other countries during past outbreaks $[39,40]$. Surveillance, diagnostic facilities and investigation of cases are important to control an outbreak, but these would be useless without trained health workforce and relevant technologies [41]. Healthcare workers face a particularly high risk of infection and death, as they are in direct contact with symptomatic patients $[42,43]$. This also creates an indirect impact on other healthcare workers who are often afraid and anxious to face rejection from their families and communities [44]. This led to additional burden, exhaustion, a rapid rate of turnover and poor management of healthcare workers [45]. There is need for ECOWAS countries to act quickly with their preparedness to manage COVID-19 particularly now that the number of cases is relatively low compared to what you have in the West. There is need to optimize medical supplies and build stronger communication and surveillance, isolation, develop testing protocols, geographical information systems (GIS) and modelling to estimate disease projections $[46,47]$.

\subsection{Global picture of COVID-19 pandemic}

Since 31 December 2019 and as of 17 March 2020, 180,159 cases of COVID-19 (in accordance with the applied case definitions and testing strategies in the affected countries) have been reported, including 7103 deaths. The deaths have been reported from China (3 226), Italy (2 158), Iran (853), Spain (309), France (148), United States (85), South Korea (81), United Kingdom (55), Japan (28), Netherlands (24), Switzerland (14), Germany (13), Philippines (12), Iraq (9), San Marino (9), International conveyance in Japan (7), Sweden (7), Australia (5), Belgium (5), Indonesia (5), Al- geria (4), Canada (4), Greece (4), Poland (4), Austria (3), India (3), Lebanon (3), Norway (3), Argentina (2), Bulgaria (2), Ecuador (2), Egypt (2), Ireland (2), Albania (1), Bahrain (1), Denmark (1), Guatemala (1), Guyana (1), Hungary (1), Luxembourg (1), Morocco (1), Panama (1), Sudan (1), Taiwan (1) and Thailand (1) [48]. Cases have been reported on the following continents:

\subsubsection{Africa}

Egypt (126), South Africa (62), Algeria (60), Morocco (37), Senegal (27), Burkina Faso (20), Tunisia (20), Ghana (6), Côte d'Ivoire (5), Ethiopia (5), Rwanda (5), Cameroon (4), Seychelles (4), Democratic Republic of the Congo (3), Kenya (3), Namibia (2), Nigeria (2), Somalia (1), Benin (1), Central African Republic (1), Congo (1), Equatorial Guinea (1), Eswatini (1), Gabon (1), Guinea (1), Liberia (1), Mauritania (1), Sudan (1), Togo (1) and United Republic of Tanzania (1) [48].

\subsubsection{Asia}

China (81 130), Iran (14 991), South Korea (8 320), Japan (824), Malaysia (553), Qatar (439), Israel (260), Singapore (243), Bahrain (221), Pakistan (187), Thailand (177), Philippines (142), Indonesia (134), Saudi Arabia (133), India (125), Iraq (124), Kuwait (123), Lebanon (120), United Arab Emirates (98), Taiwan (67), Vietnam (61), Brunei Darussalam (54), Palestine* (39), Sri Lanka (29), Cambodia (24), Oman (24), Afghanistan (21), Jordan (16), Maldives (13), Kazakhstan (11), Uzbekistan (8), Bangladesh (5), Bhutan (1), Mongolia (1) and Nepal (1) [48].

\subsubsection{America}

United States (4 661), Canada (424), Brazil (234), Chile (156), Peru (86), Mexico (82), Panama (69), Argentina (65), Ecuador (58), Colombia (57), Costa Rica (41), Venezuela (33), Uruguay (29), Bolivia (11), Dominican Republic (11), Jamaica (10), Paraguay (9), Honduras (8), Guatemala (6), Trinidad and Tobago (5), Cuba (4), Guyana (4), Saint Lucia (2), Antigua and Barbuda (1), Bahamas (1), Saint Vincent and the Grenadines (1) and Suriname (1) [48].

\subsubsection{Europe}

Italy (27 980), Spain (9 191), France (6 633), Germany (6 012), Switzerland (2 200), United Kingdom (1 543), Netherlands (1 413), Norway (1 169), Sweden (1 121), Belgium (1 085), Austria (1 016), Denmark (932), Greece (352), Czech Republic (344), Portugal (331), Finland (272), Slovenia (253), Ireland (223), 
Estonia (205), Iceland (199), Romania (184), Poland (177), San Marino (102), Russia (93), Slovakia (84), Luxembourg (81), Bulgaria (62), Serbia (57), Croatia (56), Armenia (52), Albania (51), Hungary (50), Turkey (47), Cyprus (40), Belarus (36), Latvia (36), Georgia (33), Malta (30), Moldova (29), Bosnia and Herzegovina (21), Azerbaijan (19), North Macedonia (19), Lithuania (17), Andorra (14), Monaco (9), Liechtenstein (7), Ukraine (5), Kosovo** (2) and Holy See (1).

\subsubsection{Oceania}

Australia (375) and New Zealand (8).

\subsubsection{Other}

International conveyance in Japan (696) [48].

\subsection{Capacity building towards preparedness to ensure cost effectiveness}

The major factors militating against effective management of pandemics include; timely detection of disease, availability of basic care, tracing of contacts, quarantine and isolation procedures and facility and poor global coordination and response mobilization [49]. The WHO has declared COVID-19 a pandemic of global public health importance. The public health response required from every nation to deal with this serious epidemic as clearly laid by the global health watchdog is simply to isolate infected persons, trace contacts, quarantine exposed persons at risk and maintain social distancing [50].

Few data are available regarding costs and costeffectiveness of pandemic preparedness and response measures, and they focus almost exclusively on hospital incident command system (HICs). The available data suggest that the greatest cost-related benefits in pandemic preparedness and response are realized from early recognition and mitigation of disease (prompt catching and stopping the sparks before they spread). Costs can be reduced if action is taken before an outbreak becomes a pandemic. Similarly, once a pandemic has begun, preventing illness generally is more costeffective than treating illness, especially because hospitalizations typically have the highest direct cost per person. High cost may also occur as a result of interventions (such as quarantines and school closures) that lead to economic disruption. These interventions may be more cost-effective during a severe pandemic. Investments to improve pandemic preparedness may have fewer immediate benefits, particularly relative to other pressing health needs in countries with heavy burdens of endemic disease. Therefore, characterizing pandemic risk and identifying gaps in pandemic preparedness are essential for prioritizing and targeting capacitybuilding efforts. Building pandemic situational awareness is complex, requiring coordination across bureaucracies, across the public and private sectors, and across disciplines with different training and different norms (including epidemiology, diagnostic services, clinical medicine, logistics, and disaster response). However, an appropriately sized and trained health workforce (encompassing laboratory or biomedical scientist, doctors, nurses, epidemiologists, veterinarians and others) that is supported by adequate coordination systems is a fundamental need. The World Health Organization has recommended a basic threshold of 23 skilled health professionals per 10,000 people [51]. Maintaining supportive care during an epidemic or pandemic can improve mortality rates by alleviating the symptoms of disease. During the 2014 West Africa Ebola epidemic, for example, evidence suggests that earlier case identification, supportive care, and rehydration therapy modestly reduced mortality [52]. Indeed, despite the unavailability of antivirals or vaccines, efforts to engage communities with added medical supplies and trained clinicians decreased the case-fatality ratio moderately as more patients trusted, sought, and received clinical care [53]. Medical supplies that may be needed for supportive care during a pandemic include hospital beds, disinfectants, ICU supplies (such as ventilators), and personal protective equipment $[54,55]$.

\subsection{The need for global concerted effort in management of pandemics}

Today, the world is facing the threat of COVID-19 pandemic that is ravaging the entire globe with associated significant mortality rate. The challenge is particularly daring in low income developing countries with fragile health infrastructure. There is need to set up a concerted global preparedness team that could work collaboratively with the WHO and the world bank to ensure that countries are better prepared to manage global health crisis. It is often common to see most countries invest less into pandemic preparedness only to end up paying hugely for their inactions. The US failed to recognize the need or value to invest in preparedness in West Africa in the early stages of the Ebola 2014 outbreak. Failure to invest in the preparedness by strengthening the health infrastructure in the affected West African countries led the government to expend- 
ing $\$ 2.4 \mathrm{~m}$ about half the total international investment to support Sierra Leone, Liberia and Guinea in their effort to arrest the 2014-2016 outbreaks. The social and economic cost of the outbreak was estimated at $\$ 53$ billion at an average of $\$ 1.8 \mathrm{~m}$ per Ebola case. A fraction of the money spent by the US could have been enough with reduced mortality if there were a timely proactive intervention rather the reactionary measures taken when after the pandemic had begun. It is becoming increasingly clear that the world is fast becoming a global village and that pandemic does not respect borders, regions, continents, skin color, ethnicity and religious affiliations [56-58]. The only strategic long-term solution is for all responsible government worldwide is to work as a team by investing significantly towards preparedness for pandemics [59]. Experience from the world's management of the Ebola crisis should strengthen our resolve to work together to make the world safer for all. In the early days of the Ebola crisis the West initially turned a blind eye believing that the pandemic was an African problem. Shortly thereafter infected persons started reach the shores of developed economies. It was then it dawned on these nations that the pandemic was a global public health problem rather than being an African problem. In the light of the ongoing COVID19 , this resilience spirit is what is required to fight this pandemic. We should all advocate for globalization and collaborative approaches by building bridges across nations and businesses with people becoming more connected and interdependent through increased economic integration, communication exchange, cultural diffusion, public health and travel [60-62]. The world needs to shift from the blame game and promote the notion of inclusiveness and working in partnerships in our response to addressing a wide array of economic, environmental, social and health problems facing the human race. There is need for a paradigm shift in global orientation. It should no longer be seen as an African, Chinese, developing countries problem but rather it should be seen as our global problem [63,64].

\subsection{Provision of support to manage economic impact of pandemics}

Pandemics can cause acute, short-term fiscal shocks as well as longer-term damage to economic growth. Early-phase public health efforts to contain or limit outbreaks (such as tracing contacts, implementing quarantines, and isolating infectious cases) entail significant human resource and staffing costs [65]. As an outbreak grows, new facilities may need to be con- structed to manage additional infectious cases; this, along with increasing demand for consumables (medical supplies, personal protective equipment, and drugs) can greatly increase health system expenditures [66]. Diminished tax revenues may exacerbate fiscal stresses caused by increased expenditures, especially in Lowand Middle-Income Countries (LMICs), where tax systems are weaker and government fiscal constraints are more severe. This dynamic was visible during the 2014 West Africa Ebola epidemic in Liberia. While response costs surged, economic activity slowed, and quarantines and curfews reduced government capacity to collect revenue [67]. Recent health disasters and epidemics including Ebola virus disease epidemic in West Africa, the Middle East Respiratory Syndrome (MERS) outbreak in the Republic of Korea, rise of antimicrobialresistant pathogens and now with the COVID-19 pandemic should get the global public health community talking and advocating for investments in global health security [68]. The public health community must wake up to current realities and work collaboratively to strengthen national systems to avoid international spread of disease, recognize that biological threats not only have global health impacts but also wide-ranging socioeconomic disruptions [69]. The UN's trade and development agency (UNCTAD) has recently reported that the slowdown in the global economy attributable to the coronavirus outbreak is likely to cost at least $\$ 1$ trillion. This is apart from the tragic human consequences of the COVID-19 coronavirus epidemic [70]. The cost of the disruptions to the GDP of China and South Korea is estimated at $\$ 17$ billion. It is glaringly clear that global emerging and endemic infectious disease events have a wider socioeconomic consequence. There is the need for critical information sharing, resources and key partnerships between governments, public and private health systems in preparation for potential infectious disease events and their socioeconomic consequences [71].

\subsection{Preventing the spread of COVID-19. West African countries must implement evidenced-based best practices}

Once a pandemic has begun in earnest, public health efforts often focus on minimizing its spread. Limiting the spread of a pandemic can help to reduce the number of total people who are infected and thus also mitigate some of the indirect health and economic effects. Strategies that countries in West Africa can implement to potentially minimize pandemic spread include the 
following; curtailing secondary infection or interactions between infected and uninfected populations (patient isolation, quarantine, social distancing practices and school closures, use of personal protective equipment, and travel restrictions), reducing infectiousness of symptomatic patients (antiviral and antibiotic treatment and infection control practices) and reducing susceptibility of uninfected individuals (effective vaccination). The practice of quarantine began in the fourteenth century in response to the Black Death and continues to be an effective tool even today [72]. Quarantine and social distancing (such as the prohibition of mass gatherings) during the 1918 influenza pandemic and the experience from the recent Chinese government drastic measure to shut down Wuhan in the face of the COVID-19 pandemic [73] has the potential to reduce spread and mortality rates, particularly when implemented in the early stages of the pandemic [74,75]. During SARS and Ebola outbreaks, health agencies and hospitals limited disease spread by isolating symptomatic patients, quarantining patient contacts, and improving hospital infection control practices [76,77]. During the 2003 SARS pandemic, none of the health care workers in hospitals in Hong Kong and China, who reported appropriate and consistent use of masks, gloves, gowns, and hand washing (as recommended under droplet and contact precautions) were infected [78]. Travel restrictions are sometimes implemented by governments to curtail disease spread. Fear and lack of scientific understanding may motivate the imposition of travel restrictions [71].

\subsection{Cost of complacency in West Africa in the face of COVID-19 pandemic is huge (experience from Iran, Italy and USA)}

Coronavirus "knows no borders neither does it distinguishes between ethnicities, continents, or faiths. These are stalk realities we are beginning to see from the poor handling of the COVID-19 pandemic in Iran. It is complacency to confuse a real pandemic with science fiction or to dismiss COVID-19 as just the flu. It is complacency for a nation like Iran to have cases of the COVID-19 spreading in their country but failed to report it. Some experts and critics of the Iranian government report that it is likely the virus is far more severe than officials are reporting, alleging that leaders have sought to cover up the full extent of the outbreak [79]. Iran didn't acknowledge the presence of coronavirus in the country until February 19. The Iranian government was slow to acknowledge the coronavirus outbreak because February 11 is the anniversary of the Islamic revolution and February 21 was already scheduled as date for parliamentary elections. The government was complacent to impose restrictions on either of these public events as it was seen as potentially damaging to a government already under pressure. As a result of this complacency and failure to report, Iran has become one of the worst-affected countries by the coronavirus pandemic, reporting nearly 1,000 deaths and more than 16,000 cases [80]. Satellite images emanating from Iran has shown the deadliness of the virus with workers been seen digging mass burial pits for weeks. Only recently, an Iranian state TV journalist said the country could see 4 million cases of COVID-19 and 3.5 million deaths if people don't comply with the government's travel warnings and guidance to socially isolate. Public complacency about COVID-19 is being promoted by the Iran and experience in this nation provides an interesting example of the difficulty of predicting how fast an epidemic can spread in the midst of denial. The coronavirus has infected a disproportionate number of Iran's elite; senior clerics, government officials and the higher echelons of the Republican Guard. There are several complacency-related factors driving the epidemic in Iran; the nation is an Islamic Republic where religion and state are intertwined, there is poor implementation of social distancing (the people interact frequently and greet one another with kisses), the nation has refused to ban social gathering particularly in the holy city of Qom where Shia pilgrims from all over the world continue to congregate in close proximity, American sanctions on Iran is putting a lot of strain on the nation as the government struggles with a shortage of medical equipment and much needed personal protective equipment.

On Jan. 31, Italy had two confirmed cases of COVID19. By Tuesday, the $17^{\text {th }}$ or March, it had more than 10,000. The Italian Government and Donald Thump tried complacency with COVID-19 and both countries are paying dearly for it. Between December 1st and February 5th, a number of direct flights went from Wuhan to Rome (28) and Paris (23) as well as to San Francisco and New York (23). The government in these countries did little or nothing to carry out due diligence on these passengers from high risk Wuhan and to encourage self-isolation of passengers on these flights. Italy is today under coronavirus lockdown and the nation is finding a fragile sense of solidarity after initially being complacent with COVID-19. The Italian prime minister, Giuseppe Conte, has recently announced that the whole of Italy was to be designated a "protected zone", and placed under lockdown as cases of COVID19 in the country rose to 9,172 , with 463 deaths. For 
the next month, until 3 April, 60 million Italians will be obliged to remain at home, and have been ordered to go outside only for "urgent" work, to attend health appointments or to purchase basic provisions. Bars and restaurants will be forced to close at $6 \mathrm{pm}$, and people have been asked to maintain a distance of a metre from one another in all public spaces. The Italian case paint a clear picture of what can potentially happen when a government become complacent and make political blunder resulting from political infighting particularly at a critical time of a pandemic or national emergency. The reactional approach and poor management of the Italian government plans to quarantine an area in the north of the country lead to thousands of people from Italy's worst-hit northern areas heading south to relatively poor regions such as Puglia and Calabria (these areas before now have been largely unaffected by the virus). This complacency has put Italy's weak, suboptimal and struggling economy and health infrastructure at even more risk [81].

Between Dec. 1 and Feb. 5, roughly the same number of direct flights went from Wuhan to Rome (28) and Paris (23) as went to San Francisco and New York (23 each). U.S. is believed to be the fifth most likely country to import COVID-19 from China, after Thailand, Japan, Taiwan and South Korea. As of Wednesday March 12, the US has seen 1,323 confirmed cases of COVID19 , the disease stemming from the coronavirus, and 38 deaths. Public health officials estimated that millions of people may eventually be infected with COVID-19. Government's top infectious disease experts including Dr. Anthony Fauci, director of the National Institute of Allergy and Infectious Diseases and a member of the White House coronavirus task force had warned that complacency and failure to readily and aggressively contain and mitigate this pandemic could increase the number of those infected. However, that same evening, President Donald Trump addressed the nation from the Oval Office and complacently downplayed the public health risk of the growing pandemic by saying that the virus was on the brink of disappearing, contradicting evidenced-based facts and statements of the government's top infectious disease experts possibly to explain out his administration initial slow response to the crisis [82]. In the midst of a looming crisis, there are two reactions that should be avoided. The first is panic and the second is complacency. Faced with the coronavirus epidemic, President Donald Thump had falling into the second [83]. President Donald Thump exhibited complacency to the COVID-19 pandemic in several ways; the government was slow to distribute tests kits meaning that fewer people were being tested (at the time of making his complacent comments less than 8,500 people have been tested in the US while South Korea was testing 15,000 per day) and the true picture of the epidemic was not immediately seen; claimed without evidence that the footprint of the virus was small and shrinking; downplayed the coronavirus as something similar to the seasonal flu; his baseless optimism that Americans should not be overly concerned about something that would quickly pass (this statement did not match the reality and evidence from health expert and U.S. public health agencies) and responded to the pandemic with denial and blaming foreigners. One obvious remedial step to curtailing the spread of the virus is by banning large gatherings (while trump was making his complacent remarks his campaign announced one in Milwaukee and a number of rock concerts, church services, and festivals were still taking place.). The president initially set unrealistic expectations. However, faced with reality of the increasing numbers of Americans infected had to face reality. Trump's denial in the face of rising cases of the COVID-19 pandemic and expert advice on the pandemic led to biggest stock market one-day crash since 1987's Black Monday crash. In the span of 48 hours, the 73 years old president was compelled to retrace his steps by releasing national emergency funds of $\$ 50 \mathrm{bn}$ to address the Coronavirus outbreak. Reality seems to be setting in as coronavirus continues to cripple businesses across the US. President Trump is coming to terms with realities on ground by recently signing into law a relief package passed by the House and approved by the Senate to provide free testing, expanded funding for food security programs and paid sick, family and medical leave for workers at companies with 500 employees or fewer.

Government in West African countries must learn from these mistakes and take real stringent measures and beef up their level of preparedness to manage this pandemic and to contain this infection. This strategy is quite vital particularly now that the number of confirmed cases in the region is still low. It is projected that Western democratic governments that have been most complacent or incompetent with the COVID-19 pandemic stands the risk of being torn to shreds by unforgiving electorates for failing to act fast and proportionately $[83,84]$. Countries in West Africa will need to heighten their surveillance capacity to rapidly test and identify imported cases and implement measures aimed at preventing secondary transmission within the community and among healthcare workers (HCW) [85]. If countries like the USA and Italy with better health 
infrastructure are paying duly for initial complacence with the COVID-19, countries in West Africa with their weak and fragile health infrastructure cannot afford to even contemplate being complacent with this COVID19 pandemic. By now one will expect countries in West Africa or indeed ECOWAS to have developed a strategic plan for management of COVID-19 (including case definition of a suspected case, provision of a fit for purpose and equipped facility for isolation, have measures in place for contact and co-exposure tracing as well as stockpiling of relevant supplies including PPE. Based on current evidence a possible case definition may be (a person presenting with a severe acute lower respiratory infection (shortness of breath), cough and fever $\left(>37^{\circ} \mathrm{C}\right)$ requiring admission to hospital with a history of travel to or residence in Wuhan, China, Iran, South Korea, Italy, Spain or other countries with significant number of COVID-19 infected cases in the 14 days before symptom onset. A confirmed case can be defined as a positive SARS-CoV-2 RT-PCR on respiratory samples, performed by an accredited laboratory by real-time RT-PCR procedure [86]. Contact or coexposed persons can be defined as persons who shared the same risks of exposure with a confirmed case of COVID-19. Contacts are traced from the date of onset of clinical symptoms in a patient with a confirmed case of COVID-19. A mechanism for active surveillance of contacts/co-exposed persons should be implemented. There should be stockpile of relevant medications and personal protective equipment (gloves, hand gloves, disposable coats and visor).

It is becoming increasingly clear that no one can predict exactly when or where the next epidemic will occur. We live in a difficult and challenging world. There is significant risk of infectious disease outbreaks with attendant socio and economic consequences. Evidence from the current COVID-19 and past epidemics like EBOLA has proven that complacency has huge socio, public health and economic implications. Despite ample evidence of this threat, little progress has been made with regards to preparedness and prompt response. Evidence has shown some level of complacency and poor preparedness with recent outbreaks (West Nile, SARS, $2009 \mathrm{H} 1 \mathrm{~N} 1$ and H5N1 influenza, MERS, Zika, the West Africa Ebola outbreak). Prompt and proactive response is what is required rather been reactive with attendant economic cost and significant loss of lives. WHO Director-General's opening remarks at the mission briefing on COVID-19 on the $26^{\text {th }}$ of February 2020 encouraged nations not to be complacent with the COVID-19 infection. When EBOLA outbreak was first reported in 2014, the international community initially was complacent because the disease was seen as an African problem. When cases of infected persons began to arrive the shores of developed countries, it dawned on the them that the world was fast becoming a global village and that concerted effort was required because what affect country one or a continent can potentially end up affecting all. West African countries must guard against complacency in the fight against the COVID-19 pandemic.

World Health Organization member states should strive to meet specific standards for detecting, reporting on, and responding to outbreaks. There was complacency by the Chinese government when this virus was first identified in Wuhan. After weeks of inaction, the Chinese authorities were pressured to mount a rapid and coordinated response to control the virus. They implemented best practices suggested by the WHO (shut down Wuhan, a city of 11 million people, tested a significant number of people, set up within a short space of time mobile testing centers and reduced turnaround times from four days to four hours thereby reducing significantly the time between the onset of symptoms to definitive laboratory result from 12 to three days. They did contact tracing and identified exposed family clusters and arranged isolation centres for exposed family clusters. The evidenced based best practice of avoiding complacency is paying off in China today as the number of cases report daily has significant reduced in a population of nearly 1.4 billion people. Also, mortality rate from the virus has also plummeted significantly. Several other countries, including South Korea, Japan, Singapore and Taiwan are beginning to implement these evidenced-based best practices/strategies with little modification to meet their peculiar local needs. This is the kind of response that is expected from member countries of ECOWAS. We have all seen how over reaching the effect of complacency can be from the case of the USA. On Wednesday the $11^{\text {th }}$ of March President Donald Trump assured Americans that the novel coronavirus was on the brink of disappearing. Two days later, faced with reality that the virus was rapidly spreading in major American cities he was pressured to admit that the virus was not at the brink disappearing after all. In the face of this reality, he released $\$ 50$ billion in government funding to address the growing crisis of the coronavirus.

\subsection{The need for ECOWAS to build local capacity for management of pandemics}

Local capacity building is vital for the effective management of pandemics. There is need for West African 
countries to leverage on experience gained in the management of the 2014 Ebola epidemic particularly from evidenced based best practice exhibited by the Nigerian government from her polio eradication efforts which facilitated the successful response and management of the few cases Ebola imported into Nigeria [87]. Previous national experience managing large scale and experience using the global positioning systems (GPS) in Nigeria, Sierra Leone and Mali facilitated contact tracing in the Ebola 2014 outbreak [88,89]. There is need for ECOWAS countries to stockpile relevant supplies and personal protective equipment (PPE) (such as nose masks, gowns, hand gloves, visor, hand sanitizers and ventilators) [90,91]. During a pandemic like we currently have with COVID-19, such stockpiles can become handy and readily available leaving the country enough time to boost local production or to purchase the needed supplies from foreign sources. There is also the need for ECOWAS countries to build local capacity for local production/manufacturing of these necessary supplies which can potentially strengthen their preparedness to manage epidemic rather than depending on other nation who may need such supplies to deal with similar challenges in the country of manufacture. We are already seeing similar situation with COVID-19 pandemic where these supplies have become very expensive and in limited (sanitizers and nose mask) supplies in most West African countries. Boosting local production capacity for necessary supplies may be a viable strategy that can facilitate better pandemic preparedness and will allow for optimum stockpiling with the option to promptly produce at short notice these consumables when there is urgent need for them. This will prevent the risk of outdating, reduced warehousing cost and loss of potency associated with short life span laboratory reagents.

\section{Evidenced based best practices countries in West Africa can implement to prevent and effectively manage the COVID-19 pandemic}

1. Wash your hands frequently with water and soap or use an alcohol-based (60\% alcohol) hand sanitizer if you have no access to water and soap.

2. Coughs and sneezes into a tissue (avoid coughing into your hand and contaminating materials that can potentially be handled by other).

3. Self-isolate at home if you develop symptoms of coronavirus (high fever, continuous cough and shortness of breath) for 7-14 days.

4. Avoid touching your eyes, nose and mouth with unwashed hands.
5. Avoid close contact with people who are unwell.

6. If you have a fever, cough and difficulty breathing, seek medical attention and call in advance.

7. If you feel unwell, stay at home, do not attend work or school.

8. Clean and disinfect frequently touched objects and surfaces in the home and work environment.

9. Maintain at least 1 -meter ( 3 feet) distance between yourself and anyone who is coughing or sneezing.

\section{Priorities for possible implementation across West Africa}

There is need for West African countries to implement the following priorities in a bid to effectively manage the COVID-19 epidemic in the region.

1. All member countries of ECOWAS must protect her suboptimal numbers of health care workers (Medical Laboratory Scientist, Doctors, Nurses, Pharmacists and other front-line healthcare workers by providing a conducive and safe environment for them to carry out their work. There is need for government to stockpile all the personal protective equipment (hand sanitizers, hand gloves, nose mask, disposable over coats and disposable visor) and other supplies (drugs, ventilators, consumables and test kits etc.) required to enable them manage patients safely and effectively to prevent widespread secondary infection and associated staff sickness absences that can potentially jeopardize the fragile public health services in the region.

2. Secondly, there is an urgently need for public enlightenment on the need for citizens not to be complacent but rather to take necessary precautions to protect themselves particularly the vulnerable members of the community (elderly and persons with underlying health conditions and comorbidities).

3. Thirdly we must do all that is humanly possible to test suspected cases and to isolate confirmed cases while making effect to trace contacts who should be encourage to self-isolate in arranged isolation centres for a minimum of 14 days. West Africa is family friendly region. The risk of the virus spreading among family clusters is very high and could fuel this epidemic. This virus spreads mainly through extended close contact. This put family members potential at risk.

4. Fourthly there is the urgent need to implement a TITTCSD (Test, Isolate, Treat, Trace Contact, 
Quarantine and Social Distancing) policy by monitoring borders across the West African region to ensure that measures are in place to determine as a minimum the temperature of persons coming into any of the member countries from abroad and to seek consent to test those presenting with symptoms of cough, fever and shortness of breath with high index of suspicion for COVID-19. Those found positive should be promptly isolated and treated. All contact to the index patients should be traced and quarantined. The population must be educated to implement social distancing. Effort must be made to contain the infection by detecting cases early; following up close contacts and prevent the secondary transmission of the disease.

5. Fifthly member countries should be able to provide statutory sick pay or relief for workers who are found positive, unable to go to work and forced into self-isolation. This will serve as incentive for persons at risk to self-isolate knowing fully well that their livelihood would not be threatened. The risk of not doing this as a priority is that persons at risk will go to the workplace in a bid not to lose their financial security and by so doing put many more lives at risk.

6. Sixthly there is need to protect vulnerable members of the public particularly elderly or senior citizens and people with pre-existing health conditions and comorbidities who are more likely to experience severe illness or potentially die from the infection.

7. Seventhly there is need for the implementation of a policy on social distancing (1 meters apart) as well as limiting public mass social gatherings and encouraging more people particular those at risk to work from home as well reduce non-essential travel.

8. Eighthly WHO recommend that blood supply be sourced from low risk voluntary non-remunerated altruistic donors. There is no evidence that SARS$\mathrm{CoV}-2$ can be transmitted through blood transfusions. It is envisaged that blood supply shortages was likely to occur within the duration of this pandemic. There is therefore the urgent need for the transfusion community to prepare accordingly. ECOWAS countries in the light of the few cases of COVID-19 in the region should put stringent measures in place to facilitate the delivery of adequate and safe supply of blood and blood products should the number of infected cases rise in the region.

9. Ninthly, there is the need for a paradigm shift in the mindset of people in West Africa. In the light of the coronavirus pandemic, a number of businesses have started advising employees to work from home in an ongoing bid to curb the coronavirus outbreak. This strategy will help keep employees further apart from each other particularly those that are self-isolating and will reduce the chance of group spread as well as reduce the opportunity for the virus to spread as people commute to work in public transport (bus, train, or tram). It is vital for government in West Africa to develop the capacity and required technology for people to potentially work from home.

\section{Conclusion}

The worldwide pandemic of the novel coronavirus SARS-CoV-2, which causes COVID-19 disease is disrupting healthcare services across the globe. Concerted effort is need to effectively manage this pandemic. Countries in West Africa tend to have suboptimal health infrastructure often due to decade of underinvestment. Only few cases of the COVID-19 infection have so far been reported so far in West Africa. This seems a heartening news. However, this should not call for complacency but rather an opportunity to invest in preparedness to manage the pandemic to ensure that the spread is put under check. There is need for the region to consolidate locally-generated evidence from the management of the Ebola epidemic in 2014 as well as evidence-based best practices from other countries like China and South Korea to develop a locally-driven strategy to effectively manage this pandemic.

There is need to build capacity to test persons presenting with symptoms (fever, cough and shortness of breath), isolate and treat those found positive, trace and quarantine contacts, implement a policy on social distancing, ensure optimum stockpiling of essential supplies including PPE, test kits, ventilators and other consumables and boosting local production capacity for necessary supplies. These are viable strategies that can facilitate better management of this COVID-19 pandemic. There is the need to strengthen our resolve as a global community to move away from a blame game and work together and collectively fight this pandemic with the hope of making the world safer for all.

\section{References}

[1] The Merriam-Webster. Complacency. https://www.merriamw ebster.com/dictionary/complacency. 
[2] K.E. Jones et al., Global trends in emerging infectious diseases, Nature 451 (2008), 990-993.

[3] World Health Organization (WHO). Novel coronavirus China. Disease outbreak news. Geneva: WHO; 2020. [Accessed: 4 Feb, 2020].

[4] European Centre for Disease Prevention and Control (ECDC). Novel coronavirus. Stockholm: ECDC; 2020. [Accessed: 12 Feb, 2020].

[5] N. Zhu et al., A novel coronavirus from patients with pneumonia in China, New England Journal of Medicine 382 (2020), 727-733.

[6] The International Committee for Taxonomy of Viruses named the causative virus SARS-CoV-2 on 7 Feb 2020.

[7] Coronavirus Disease 2019 (COVID-19). Centers for Disease Control and Prevention (CDC). 15 February 2020. Archived from the original on 26 February 2020. Retrieved 20 February 2020.

[8] Statement on the second meeting of the International Health Regulations (2005) Emergency Committee regarding the outbreak of novel coronavirus (2019-nCoV). World Health Organization (WHO). Archived from the original on 31 January 2020. Retrieved 11 February 2020.

[9] World Health Organization, Coronavirus disease 2019 (COVID-19): situation report, 47. World Health Organization (WHO). hdl:10665/331444. The WHO declared the 2019-20 coronavirus outbreak a pandemic, March, 2020.

[10] D.S. Hui et al., The continuing 2019-nCoV epidemic threat of novel coronaviruses to global health - The latest 2019 novel coronavirus outbreak in Wuhan, China, International Journal of Infectious Disease 91 (2020), 264-266.

[11] E. Alexander et al., Severe acute respiratory syndrome-related coronavirus: The species and its viruses - a statement of the Coronavirus Study Group. bioRxiv 2020.02.07.937862; doi: 10.1101/2020.02.07.937862.

[12] National Health Commission. 7 February 2020. Archived from the original on 28 February 2020. Retrieved 9 February 2020 National Health Commission. 7 February 2020. Archived from the original on 28 February 2020. Retrieved 9 February 2020.

[13] European Centre for Disease Prevention and Control. An agency of the European Union. Situation update worldwide, as of 18 March 2020. https://www.ecdc.europa.eu/en/geographi cal-distribution-2019-ncov-cases.

[14] World Population Prospects: Overall total population - The 2019 Revision (xslx). population.un.org (custom data acquired via website). United Nations Department of Economic and Social Affairs, Population Division. Retrieved November 9, 2019.

[15] United Nations, Department of Economic and Social Affairs, Population Division, World Population Prospects 2019: Data Booklet (ST/ESA/SER.A/424), 2019.

[16] United Nations Department of Economic and Social Affairs, Population Division (2017). World Population Prospects: The 2017 Revision, custom data acquired via website.

[17] WHO Strengthening health systems to improve health outcomes: WHO's framework for action Geneva, 2007.

[18] D.W. Brinkerhoff and T.J. Bossert, Health Governance: Concepts, Experience, and Programming Options, Bethesda: Abt Associates Inc; 2008.

[19] J.J. Guilbert, The world health report 2006: Working together for health, Education and Health (Abingdon) 19 (2006), 385387.

[20] P.W. Gething et al., Improving imperfect data from health management information systems in Africa using space-time geostatistics, PLoS Medicine 3 (2006), e271.
[21] A. Preker and J.C. Langenbrunner, Spending wisely: buying health services for the poor, Washington, D.C.: The World Bank; 2005.

[22] K.M. Kirigia and C. Wambebe, Status of national health research systems in ten countries of the WHO African Region, BMC Health Services Research 19 (2006), 135.

[23] J.M. Kirigia et al., Technical efficiency, efficiency change, technical progress and productivity growth in the national health systems of continental African countries, Eastern Africa Social Science Research Review 23 (2007), 19-40.

[24] P.E. Mbondji, Overview of national health research systems in sub-Saharan Africa: Results of a questionnaire e-based survey, Journal of the Royal Society of Medicine 107 (2014), 46-54.

[25] D. McIntyre and G. Mooney, The economics of health equity, Cambridge: Cambridge University Press; 2007.

[26] B. O'Hare, Weak health systems and Ebola, The Lancet Global Health 3 (2015), PE71-E72.

[27] J.M. Kirigia and S.P. Barry, Health challenges in Africa and the way forward, International Archives of Medicine 1 (2008), 27.

[28] WHO Strengthening health systems to improve health outcomes: WHO's framework for action Geneva. 2007.

[29] D. Kebede et al., Progress on the health-related MDGs in the African Region, African Health Monitor 10 (2010), 10-17.

[30] A. Rahman and A. Shaban, African News. https://www.africa news.com/2020/03/16/four-african-countries-confirmed-firstcoronavirus-cases-in-a-day-list//.

[31] S. Defor et al., Understanding the state of health policy and systems research in West Africa and capacity strengthening needs: Scoping of peer-reviewed publications trends and patterns 1990-2015, Health Research Policy and Systems 15 (2017), 55.

[32] L. Gostin, Ebola: Towards an international health systems fund, Lancet 384 (2014), e49-e51.

[33] H. Shoman et al., The link between the West African Ebola outbreak and health systems in Guinea, Liberia and Sierra Leone: A systematic review, Global Health 13 (2017), 1.

[34] S. Bellizzi, The current Ebola outbreak: Old and new contexts, Journal of Infectious Diseases of Developing Countries 8 (2014), 1378-1380.

[35] WHO, Monitoring the building blocks of health systems: a handbook of indicators and their measurement strategies. World Health Organization Library Cataloguing-in-Publication Data. 2010.

[36] A.G.S. Buseh et al., The Ebola epidemic in West Africa: Challenges, opportunities, and policy priority areas, Nursing Outlook 63 (2015), 30-40.

[37] E. Polich, The link between the 2015/2015 Ebola outbreak and health systems in Guinea, Liberia and Sierra Leone. $\mathrm{H}$. Shoman, ed. August 12th 2015.

[38] C. Atchison, The link between the 2014/2015 Ebola outbreak and health systems in Guinea, Liberia and Sierra Leone. $\mathrm{H}$. Shoman, ed. 7th August 2015.

[39] A. Gulland, More health staff are needed to contain Ebola outbreak, warns WHO, British Medical Journal 349 (2014), 5485 .

[40] A. De Frey, Letters in the time of Ebola, Travel Med Infect Dis 12(5) (2014), 541-542.

[41] F.B. Chiappelli et al., Ebola: Translational science considerations, Journal of Translational Medicine 13 (2015), 11.

[42] S.H. Barnes et al., The view from the Ebola Treatment Centre, Makeni, central Sierra Leone, Emerging Medicine Journal 32 (2015), 571-573.

[43] V. Wiwanitkit, Unprecedented scale Ebola epidemic in Guinea: 
What we should know, Asian Pacific Journal of Tropical Biomedicine 4 (2014), 67.

[44] J.G. Weyer et al., Ebola virus disease: History, epidemiology and outbreaks, Current Infectious Disease Report 17 (2015), $1-8$.

[45] C. Lewis, The link between the 2014/2015 Ebola outbreak and health systems in Guinea, Liberia and Sierra Leone. H. Shoman, ed. 28th August 2015.

[46] Y.S. Butler, Ebola virus: Exposing the inadequacies of public health in Liberia, Mayo Clinical Proceedings 89 (2014), 15961598 .

[47] C.A. Brown et al., Ebola virus disease: The 'Black Swan' in West Africa, Tropical Doctor 45 (2015), 2-5.

[48] European Centre for Disease Prevention and Control. An agency of the European Union. Situation update worldwide, as of 17 March 2020 08:00. https://www.ecdc.europa.eu/en/geog raphical-distribution-2019-ncov-cases.

[49] S. Moon et al., Will ebola change the game? Ten essential reforms before the next pandemic. The report of the harvard - LSHTM independent panel on the global response to ebola, The Lancet 386 (2015), 2204-2221.

[50] M.S. Smolinsky et al., Microbial Threats to Health: Emergence, Detection, and Response, Washington, DC: National Academies Press, 2003.

[51] J.E. Fischer and R. Katz, Moving forward to 2014: Global IHR (2005) implementation, Biosecurity and Bioterrorism: Biodefense Strategy, Practice, and Science 11 (2013), 153156.

[52] N.F. Walker and C.J. Whitty, Tackling emerging infections: Clinical and public health lessons from the west african ebola virus disease outbreak, Clinical Medicine 15 (2015), 457-460.

[53] B. Aylward et al., Ebola virus disease in west africa - the first 9 months of the epidemic and forward projections, New England Journal of Medicine 371 (2014), 1481-1495.

[54] WHO (World Health Organization). "WHO Model List of Essential Medicines, 19th ed." WHO, Geneva, 2015b.

[55] N. Madhav et al., Pandemics: Risks, Impacts, and Mitigation. Chapter 17. In Disease Control Priorities: Improving Health and Reducing Poverty. 3rd edition, 2017.

[56] V.K. Dixon, Understanding the implications of a global village, Inquiries Journal/Student Pulse 1(11) (2009). http://www. inquiriesjournal.com/a?id=1681.

[57] R.S. Hunt, Health care management in the global village. Frontiers of health services management. Academic Journal Article 11 (1994).

[58] K.J.C. Rajendra and H. Alfonso, Defining and developing a global public health course for public health graduates, Frontiers of Public Health, 01 July 2015. doi: 10.3389/fpubh.2015. 00166.

[59] E.M. Meslin and I. Garba, International Collaboration for Global Public Health, 2016 Apr 13, in: H.D. Barrett, W.L. Ortmann, A. Dawson et al., eds. Public Health Ethics: Cases Spanning the Globe [Internet], Cham (CH): Springer, 2016. Chapter 8. Available from: https://www.ncbi.nlm.nih.gov/ books/NBK435788/. doi: 10.1007/978-3-319-23847-0_8.

[60] P. Godoy-Ruiz et al., Developing collaborative approaches to international research: Perspectives of new global health researchers, Global Public Health 11 (2016), 253-275.

[61] Globalization Knowledge Network Towards health-equitable globalization: Rights, regulation and redistribution. Final report to commission on social determinants of health, 2007.

[62] R. Labonté et al., Framing international trade and chronic disease, Global Health 7 (2011), 21.

[63] D. Horton, G. Prain and G. Thiele, Perspectives on partner- ship: A literature review. Lima: International Potato Center, CIP, 2009.

[64] B. Jentsch and C. Pilley, Research relationships between the South and the North: Cinderella and the ugly sisters? Social Science and Medicine (2003), 1957-1967.

[65] C. Achonu et al., The financial impact of controlling a respiratory virus outbreak in a teaching hospital: Lessons learned from SARS, Canadian Journal of Public Health 96 (2005), $52-54$.

[66] J.J. Herstein et al., Initial costs of ebola treatment centers in the united states, Emerging Infectious Diseases 22 (2016), 350

[67] O.B. Jonas, Pandemic Risk, Background paper for World Development Report 2014: Risk and Opportunity; Managing Risk for Development, World Bank, Washington, DC 2013.

[68] K.M. Smith et al., Infectious disease and economics: The case for considering multi-sectoral impacts, One Health (Amsterdam, Netherlands) 7 (2019), 100080.

[69] United Nations Development Group - Western and Central Africa, Socio-Economic Impact of Ebola Virus Disease in West African Countries 2015.

[70] World Economic Forum, This is how much the coronavirus will cost the world's economy, according to the UN. www. weforum.org/agenda/2020/03/coronavirus-covid-19-costeconomy-2020-un-trade-economics-pandemic/.

[71] J.W. Lee and W.J. McKibbin, Estimating the Global Economic Costs of SARS, in: Institute of Medicine (US) Forum on Microbial Threats; S. Knobler, A. Mahmoud, S. Lemon et al., eds. Learning from SARS: Preparing for the Next Disease Outbreak: Workshop Summary. Washington (DC): National Academies Press (US); 2004. Available from: https://www. ncbi.nlm.nih.gov/books/NBK92473/.

[72] P.A. Mackowiak and P.S. Sehdev, The origin of quarantine, Clinical Infectious Diseases 35 (2002), 1071-1072.

[73] S. Nebehay, Threat of coronavirus pandemic 'has become very real': WHO's Tedros. World News. March 9, 2020. https:// www.reuters.com/article/us-health-coronavirus-who/threatof-coronavirus-pandemic-has-become-very-real-whostedros-idUSKBN20W2GX.

[74] M.C.J. Bootsma and N.M. Ferguson, The effect of public health measures on the 1918 influenza pandemic in U.S. cities, Proceedings of the National Academy of Sciences of the United States of America 104 (2007), 7588-7593.

[75] T.D. Hollingsworth et al., Travel restrictions control the international spread of pandemic influenza? Nature Medicine 12 (2006), 497-499.

[76] N.J. Cohen et al., Travel and border health measures to prevent the international spread of ebola, Morbidity and Mortality Weekly Report (MMWR) Supplements 65 (2006), 57-67.

[77] S.J. Twu et al., Control measures for severe acute respiratory syndrome (SARS) in Taiwan, Emerging Infectious Diseases 9 (2003), 718-720.

[78] W.H. Seto et al., Effectiveness of precautions against droplets and contact in prevention of nosocomial transmission of severe acute respiratory syndrome (SARS), The Lancet 361 (2003), $1519-1520$.

[79] I. John, Coronavirus: Why COVID-19 is ripping through Iran as critics call for Tehran to do more. News. 13 March 2020

[80] S.J. Frantzman, Iran's theocracy is in denial about coronavirus threat. Jerusalem Post February 27th 2020.

[81] J. Mackay, The Guardian, Under coronavirus lockdown, Italy is finding a fragile sense of solidarity. www.theguardian.com/ commentisfree/2020/mar/10/coronavirus-lockdown-italyflorence-panic.

[82] G. Orr and N. Cook, From complacency to emergency: How 
Trump changed course on coronavirus. Politico Dispatch. EP15. POLITI 03/14/2020 05:50 PM EDT. Updated: 03/14/ 2020 08:10 PM EDT.

[83] S. Chapman, A Dangerous Complacency about Coronavirus. The National Memo. March 14th 2020.

[84] B.S. Sibylle et al., First cases of coronavirus disease 2019 (COVID-19) in France: Surveillance, investigations and control measures, January 2020, Euro Surveillance 25 (2020), 2000094.

[85] V.M. Corman et al., Detection of 2019 novel coronavirus (2019-nCoV) by real-time RT-PCR, Euro Surveillance 25 (2020), 2000045.

[86] Y.G. Yehualashet et al., Strategic engagement of technical surge capacity for intensified polio eradication initiative in nigeria, 2012-2015, Journal of Infectious Diseases 213 (2016), S116-S23.

[87] F. Shuaib et al., Ebola virus disease outbreak - Nigeria, July - September 2015, Morbidity and Mortality Weekly Report (MMWR) 63 (2014), 867-872.
[88] WHO (World Health Organization), Successful Ebola Responses in Nigeria, Senegal, and Mali. In One Year into the Ebola Epidemic: A Deadly, Tenacious, and Unforgiving Year. Paper Series, January 2015, WHO, Geneva.

[89] N. Dimitrov et al., Optimizing tactics for use of the U.S. antiviral strategic national stockpile for pandemic influenza, PloS One 6 (2011), e16094.

[90] L.C. Jennings et al., Stockpiling pre-pandemic influenza vaccines: A new cornerstone of pandemic preparedness plans, The Lancet Infectious Diseases 8 (2008), 650-658.

[91] L.J. Radonovich et al., Stockpiling supplies for the next influenza pandemic, Emerging Infectious Diseases 15 (2009), e1.

[92] World Economic Forum. This is how much the coronavirus will cost the world's economy, according to the UN. www. weforum.org/agenda/2020/03/coronavirus-covid-19-costeconomy-2020-un-trade-economics-pandemic/. 